\title{
MODIFICACIONES AL DERECHO DE PROPIEDAD EN LA LEGISLACION DE REFORMA AGRARIA
}

\section{Introducción}

La concepción de Reforma Agraria adoptada por el presente Gobierno ha traído una serie de sustanciales modificaciones en los aspectos sociales, económicos, políticos y legales. Nuestra intención en el presente trabajo es ocuparnos de los últimos - los cambios legales- en relación al derecho de propiedad sobre bienes inmuebles tal como fue legislado por el Código Civil.

El artículo 19 del D.L. 17716 nos indica cual es el contenido de este cambio legal: "La Reforma Agraria es un proceso integral y un instrumento de transformación de la estructura agraria del pais; destinado a sustituir los regímenes del latifundio y minifundio por un sistema justo de propiedad, tenencia y explotación de la tierra...".

Son importantes de mencionar dos cosas:

1. Que la Reforma Agraria está destinada a sustituir determinados regímenes de propiedad y tenencia de la tierra por otros más justos, es decir, que se busca modificar, mediante la sustitución de las reglas sobre tenencia y propiedad existentes, un injusto sistema de distribución de la tierra agrícola en el país.

2. La parte final de la cita vincula tres conceptos que tienen una clara distinción en Derecho: propiedad, tenencia y explotación.

Como veremos posteriormente, la Ley de Reforma Agraria trata efectivamente de unir, mediante mecanismos muy estrictos, la propiedad la tenencia y la explotación de la tierra agrícola.

Pero el artículo 1ㅇ del D.L. 17716 señala, además, cuáles son las finalidades de la Reforma Agraria:
- Contribuir al desarrollo social y económico de la Nación.

- Creación de un ordenamiento agrario que garantice la justicia social en el campo.

-Aumento de la producción y la productividad en el sector agropecuario.

- Lograr que la tierra constituya, para el hombre que la trabaja, base de su estabilidad económica, fundamento de su bienestar y garantía de su dignidad y libertad.

Aunque los cuatro conceptos enumerados son bastante claros y no se requiere redundar en ellos, la ley vuelve a señalar al trabajador de la tierra como destinatario de los beneficios que ella produce. Esta idea se transforma en el fundamento del derecho de propiedad sobre las tierras agrícolas.

Finalmente, dentro de las mismas normas generales hay dos que cabe resaltar:

1. El inciso a) del artículo $3{ }^{\circ}$, que señala como un deber de la legislación sobre Reforma Agraria el regular el derecho de propiedad de la tierra a fin de que se use en armonía con el interés social así como el señalar sus limitaciones; y,

2. El inciso $f$ ) del mismo artículo $3^{\circ}$ que, aparte de anunciar restricciones al derecho de propietario en el disfrute y la disposición de sus tierras, señala literalmente que una finalidad de la Reforma Agraria, y por tanto de sus leyes, es "... que la tierra sea de quien la trabaja".

Concluyendo, podemos decir que la Reforma Agraria tiene como finalidad la creación de un orden social y económico más justo a través de la regulación del derecho de propiedad sobre los inmuebles rústicos, a fin de que la tierra se use en armonía con el inte- 
rés social y que su propiedad sea de aquél que la trabaja.

\section{Adquisición y conservación de la propiedad rús- tica}

Una vez realizada una aproximación general al tema, analizaremos algunas modificaciones sustanciales del derecho de propiedad hechas por la legislación agraria vigente en relación a las normas que establecia el Código Civil.

\section{Conducción directa}

Según el artículo $8^{\circ}$ del D.L. 17716, para tener derecho a la conservación de la propiedad, no basta el justo título del derecho civil. Es también indispensable trabajar la tierra, no dejarla inculta durante un plazo determinado.

Así, quien no trabaja la tierra por si o por otro en su nombre, pierde la propiedad por abandono si transcurre el plazo de ley. Prueba de ello es que el primer párrafo del artículo $9^{\circ}$ del Decreto-Ley 17716 establece que el abandono se declarará administrativamente.

De lo dicho podemos concluir que para la conservación de la propiedad de las tierras agrarias no basta sólo el tener justo título, sino que es indispensable trabajar directamente la tierra; de lo contrario el derecho de propiedad se extingue y será declarado administrativamente el abandono.

Sin embargo, el trabajo de la tierra no sólo mantiene o extingue la propiedad sobre las tierras según sea o no efectuado sino que, aquél que la trabaja sin ser propietario, tiene la capacidad de adquirir el dominio de la tierra o, al menos, un derecho preferente a él.

El último párrafo del artículo $8^{\circ}$ del D.L. 17716 establece que quien posee tierras rústicas en la forma que señala el mismo artículo $8^{\circ}$ durante cinco años, las adquiere por prescripclón. Con ello señala como requisito indispensable para la usucapión rural que se trabaje la tierra mediante las formas previstas por la legislación agraria. En caso de que una persona diese usos distintos a los señalados por el artículo $8^{\circ}$ a una parcela agrícola, no la adquirirá por prescripción aunque transcurra el plazo de ley.

En lo que a derechos preferenciales se refiere, ci tamos a modo de ejemplo los artículos $19^{\circ}$ y $188^{\circ}$ del D.L. 17716, el artículo $3^{\circ}$ del D.L. 18833 y el artículo 70 \% del D.S. 165-69-AG.

En conclusión podemos decir que la legislación agraria ha hecho una modificación sustancial del concepto de propiedad, estableciendo que quién no trabaja la tierra por si o por otro a su nombre durante un determinado plazo pierde automáticamente su derecho de propiedad. Viceversa, quien trabaja la tierra, la adquiere por prescripción si actúa como propietario durante cinco años. En otros casos, mediante el trabajo de la tierra se adquiere un derecho preferente a su dominio.

\section{Prescripción adquisitiva}

Dos modificaciones trae la legislación agraria al Código Civil respecto a esta institución.

Primero, elimina las circunstancias subjetivas que intervienen en la prescripción adquisitiva tradicional y que originan la variación del plazo entre la prescripción larga y la prescripción corta, segundo, reduce el plazo de la legislación civil de diez o treinta años según haya buena o mala fe, a cinco años.

La prescripción adquisitiva resulta asi fortalecida y estricta para permitir el trabajo de la tierra y el acceso a la propiedad por quién verdaderamente la trabaja.

\section{Abandono: ¿Prescripción extintiva?}

El abandono, institución que extingue el derecho de propiedad, se da en dos supuestos:

-Que la tierra no sea trabajada durante tres años consecutivos por el propietario o por otro a su nombre mediante el ejercicio de actos posesorios consignados en el artículo $8^{\circ}$ del D. L. 17716.

-Que la tierra haya sido trabajada más de un año por campesino que no tenga vínculo contractual con el propietario, sin que éste hubiere interpuesto la acción judicial respectiva.

Aunque la asimilación de figuras nuevas a otras tradicionales siempre genera confusiones conceptuales, es importante señalar que el abandono extingue el derecho de propiedad, funcionando como una especie de prescripción extintiva de un derecho real.

El abandono, por otra parte, garantiza el cumplimiento de una finalidad esencial de la Reforma Agraria: que la tierra sea trabajada y que la propiedad de la tierra está indisolublemente unida a su tenen- 
cia y explotación. Si esto no se lleva a cabo, la ley sanciona extinguiendo el derecho de propiedad.

Es importante mencionar el rigor de la figura en función de lo preceptuado por el artículo $1^{\circ}$ del D.L. 18236 en el sentido de que una tierra no cultivada durante un año se entiende no cultivada por tres años, salvo prueba en contrario del propietario. Con ello se fuerza al dueño a trabajar la tierra en forma ostensible para evitar la extinción de su derecho.

\section{Pérdida de la propiedad por uso antisocial de la tierra}

El uso antisocial de la propiedad, tradicionalmente, sólo ha dado lugar a la multa o castigo al propietario. Nunca dio paso a la expropiación. Cosa diferente sucede con la legislación agraria, donde es causal de pérdida de la propiedad rural.

El arlículo $15^{\circ}$ del D. L. 17716 establece los casos de uso antisocial:

"Artículo 15\%.-Para los efectos del cumplimiento del artículo $34^{\circ}$ de la Constitución del Estado, se considera que la propledad rural no se usa en armonía con el interés social en cualesquiera de los siguientes casos:

a.-Abandono de la tierra o deficiente explotación, asi como el mal manejo y deterioro de los recursos naturales.

b.-Subsistencia de formas antisociales o feudatarias de explotación de la tierra.

c.-Condiciones injustas o contrarias a la Ley en las relaciones de trabajo.

d.-Concentración de la tierra de manera tal que constituya un obstáculo para la difusión de la pequeña y mediana propiedad rural y que determine la extrema o injusta dependencia de la población respecto del propietario.

e.-El minifundio o la fragmentación del predio en forma que determine el mal uso o la destrucción de los recursos naturales, asi como el bajo rendimiento de los factores de la producción".

Salvo el minifundio, que por sus propias caracteristicas recibe un tratamiento especial, todas las demás situaciones son sancionadas con la pérdida o extinción (caso del abandono ya estudiado) del derecho de propiedad.
Deficiente explotación. Se entiende por tierras deficientemente explotadas "aquellas en que se hace mal uso de los recursos naturales que determine su destrucción, o los rendimientos del cultivo predominante en el predio sean inferiores al ochenta por ciento $(80 \%)$ del rendimiento promedio de la zona'. El D.S. 163-69-AP, en sus arts. $15^{\circ}, 16^{\circ}, 17^{\circ}$ y $18^{\circ}$ ha reglamentado el concepto de deficiente explotación.

Lo importante para nosotros, sin embargo, es que la deficiente explotación de una tierra es causal de expropiación total en virtud de lo establecido por el artículo 16 \% del D.L. 17716.

Tierras ociosas. Son tierras que "... no han sido cultivadas durante el año agrícola anterior a la afectación si se trata de tierras de bajo riego; o han permanecido sin que se haya efectuado en ellas labores de preparación del suelo durante los dos años agrícolas anteriores a la afectación tratándose de tierras de cultivo de secano; o cuando no haya habido ganado en los dos años anteriores a la afectación si se trata de tierras cubiertas por pastos naturales, salvo que en este último caso se demuestre fehacientemente con la existencia de los cercos necesarios que los pastos están en proceso de recuperación o repoblación de las praderas" (Art. 149 del D.S. 163-69-AP).

Esta situación, intermedia entre el abandono y la deficiente explotación, constituye también causal de afectación total del predio de acuerdo al artículo $16^{\circ}$ del D.L. 17716.

Es verdad que con la disposición del artículo 1 ? del D.L. 18296 (presunción de abandono juris tantum por no haberse explotado durante un año el predio) esta causal disminuye su importancia puesto que, a diferencia del abandono, la calificación de tierra ociosa no extingue el dominio sino que es causal de expropiación. Sin embargo, tiene aún importancia para evitar que las tierras dejen de explotarse.

Formas antisociales o feudatarias de explotación de la tierra. El artículo $18^{\circ}$ del D.L. 17716 establece que "Son feudatarios, los colonos, yanaconas, aparceros, arrendires, allegados, mejoreros, precarios, huachilleros y otras formas similares de explotación directa de la tierra, vinculada a la prestación de servicios personales con retribución salarial o sin ella".

El artículo 17\% del D.L. 17716 establece la afectación total del área conducida por feudatarios y otros campesinos no propietarios. 
Condiciones contrarias a la ley en las relaciones de trabajo. El artículo 45? del D.L. 17716 establece que serán expropiados los predios en los que existan condiciones contrarias a la legislación laboral, estén dentro o fuera de zona de Reforma Agraria, pudiendo reducirse el mínimo inafectable. Luego, por R.S. 12770-TR de 29 de mayo de 1970 y por R.S. 184-70-TR de 31 de julio de 1970, se estableció que era competencia de las Autoridades de Trabajo el conocimiento de las acciones referidas a esta situación, señalándose un procedimiento ad hoc $y$ las situaciones que deberian considerarse contrarias al Derecho del Trabajo.

Concentración de la tierra. El régimen de expropiación por concentración excesiva de la propiedad de la tierra está consignado en los artículos $28^{\circ}$ a $35^{\circ}$ del D.L. 17716.

En ellos se establecen minimos inafectables diferenciales según se trate de tierras de cultivo bajo riego, secano, pastos naturales, etc. También están legislados en función de la situación geográfica de las tierras (Costa y Sierra, ya que la región selvática no está incluida en la Reforma Agraria).

En la Costa, con tierras bajo riego, el mínimo inafectable es de ciento cincuenta hectáreas. En la Sierra varia de provincia a provincia entre las cincuenticinco y las quince hectáreas.

Cada hectárea de terreno bajo riego equivale a dos de secano para efectos del mínimo inafectable.

Además, dicho mínimo puede ampliarse en su extensión si se cumplen determinadas condiciones impuestas por la ley, previa solicitud del interesado.

De esta manera, la Ley de Reforma Agraria sanciona la concentración excesiva de tierra con la expropiación forzosa. Es función esencial de la Reforma Agraria difundir y promover la pequeña y mediana propiedad, la que está determinada por los minimos inafectables señalados en cada caso.

Minifundio. Los problemas del minifundio son diferentes a los señalados en los casos anteriores. Por tanto se exigen respuestas y soluclones también diferentes.

Dado que el minifundista es normalmente un campesino que conduce directamente una parcela peque$\tilde{n ̃ a}$, en condiciones sociales y económicas precarias, la ley prevé un régimen especial que es el siguiente:
- Se prohibe la fragmentación de predios en unidades resultantes menores a la Unidad Agrícola Familiar que, según la ley, no puede ser menor de tres hectáreas en ningún caso.

- Se crea un sistema de reordenación e integración parcelaria para el cual, dado el caso, se procederá a expropiar pequeñas parcelas a fin de reagrupar propiedades y distribuir racionalmente a los campesinos en los valles.

En este sentido, el uso de la propiedad en armonía con el interés social establece limitaciones al derecho de propiedad al impedir la subdivisión de tierras en la forma antedicha y al autorizar la expropiación forzosa con fines de integración y reordenación parcelaria.

\section{Predominancia de la realidad sobre las formalida- des legales}

Con la finalidad de evitar fraudes a la Ley Agraria a través de la adopción de formas legales de propiedad que permitan legalizar el latifundio, o transmisiones de propiedad que formalmente establezcan diferentes propietarios pero que real y económicamente mantengan la unidad de la propiedad, la Ley General de Reforma Agraria ha establecido mecanismos para interpretar los hechos no en base a las formalidades legales sino en base a su real significación social y económica.

Cuatro ejemplos de ello son los siguientes:

Artículo $23{ }^{\circ}$ del D.L. 17716. Establece una presunción de pleno derecho en el sentido de considerar como un solo predio de propiedad de una persona natural, diferentes predios de propiedad de diversas personas jurídicas, siempre que la persona natural a quien se atribuye la propiedad, por si sola o por parientes dentro del cuarto grado de consanguinidad o segundo de afinidad, disponga de la propiedad o de la administración legal de un cuarenta por ciento o más de la (o las) personas jurídicas propietarias de dichos predios.

Esta norma, que para el derecho tradicional de propiedad recogido en el Código Civil hubiera sido heterodoxa, cobra plena vigencia en el Derecho Agrario superando las formalidades legales a fin de evitar que, aún a través de las Sociedades de Personas del Derecho Agrario, haya socios que disfracen la existencia del latifundio. 
Artículo 249 del D.L. 17716. Establece este artículo: "Para los efectos de la afectación se considerará como un solo predio todas las tierras de cultivo o de pastos naturales ubicados en las regiones de la Costa, Sierra y Ceja de Selva, de propiedad de una sola persona natural o juridica. Se considera asimismo como un solo predio las tierras pertenecientes a la sociedad conyugal y los bienes propios de cada cónyuge, inclusive cuando hubiere solamente separación de bienes.

La importancia de estas normas es capital. Al considerar como un solo predio los de propiedad de una misma persona, se logra que el mínimo inafectable no esté determinado por cada predio sino por cada propietario. En el caso de la sociedad conyugal, aunque la legislación civil establece diversas clases de bienes con diversos propietarios dentro del matrimonio, según sean bienes propios 0 bienes comunes, la legislación agraria vuelve a preferir la unidad económica de la propiedad antes que la diversidad formal

Se establece, incluso, que se considerará la unidad de la propiedad aún en el caso de separación de bienes. El criterio es el mismo: la sociedad conyugal, sus derechos y obligaciones permanecen en 10 que no son incompatibles con la nueva situación.

Articulo $2^{\circ}$ del D.S. 049-70-AG. Este artículo manda considerar no realizadas las parcelaciones por iniciativa privada en los casos en que el integro de las parcelas han sido adquiridas por parientes dentro del cuarto grado de consanguinidad o segundo de afinidad.

Como es sabido, las parcelaciones por iniciativa privada fueron realizadas en la mayoría de los casos, si no en su totalidad, para evitar la afectación por aplicación del mínimo inafectable, repartiendo una gran extensión de tierra en pequeñas parcelas que fueron transferidas en propiedad a personas muy vinculadas entre sí, a fin de mantener la unidad de explotación $y$, por ende, el latifundio.

La norma mencionada viene, por tanto, a no reconocer como realizadas, por presunción de pleno derecho, parcelaciones y traslaciones de dominio que fueron formalmente válidas, anteponiendo nuevamente a las formalidades jurídicas, criterios de justicia e interés social en lo que a latifundio y sus formas encubiertas se refiere.
Artículo 108 \% del D.L. 17716. Establece una autorización para la transferencia de parcelas o predios rústicos con la condición de que el adquirente no ejercerá su derecho autónomamente, sino que quedará sujeto a la afectación a que hubiere lugar, de acuerdo a la situación del enajenante a la fecha de declaración de Zona de Reforma Agraria y a las demás limitaciones establecidas, "sin considerar, en consecuencia, la situación del nuevo propietario".

En caso de cumplirse el supuesto de la norma, el derecho de propiedad deja de ser un derecho autónomo al ser transmitido; para efectos de la afectación a que hubiere lugar, el nuevo propietario no adquiere una relación definida y diferente con el objeto de su derecho sino que está sujeto a la situación de su enajenante.

Todas las diferencias de trato legal que hasta aquí hemos anotado respecto a la adquisición y conservación del derecho de propiedad sobre inmuebles rústicos, expresan con claridad las concepciones tan diferentes que guían al Derecho Civil y al Derecho Agrario en esta materia. Sin embargo, no queda alli este tratamiento diferente. Se extiende también a los derechos emergentes del derecho de propiedad.

\section{Medificaciones en los derechos que otorga el dere- cho de propiedad}

Según el artículo $850^{\circ}$ del Código Civil, el propietario de un bien tiene derecho a poseerlo, percibir sus frutos, reivindicarlo y disponer de él dentro de los límites de la ley.

Encausado dentro de la doctrina civil francesa, el Código Civil no pone más cortapisas al ejercicio de estos derechos que las señaladas en los artículos $856^{\circ}$ y siguientes, las cuales responden a necesidades elementales de convivencia. Cualquier otra forma, fuera de lo consignado en dichas normas, de ejercer el derecho de propiedad estaba permitida. Tal vez la única limitación adicional sería el abuso del derecho legislado en el artículo II del Título Preliminar del Código Civil. Esta norma, sin embargo, debido a su generalidad y a la falta de consenso que en torno a ella existe, es de muy limitada aplicación para controlar el exceso en el ejercicio de los derechos.

En lo que resta del trabajo, analizarcmos las diferencias de tratamiento que, en lo que a estos derechos emergentes de la propiedad, traen las normas de Reforma Agraria con respecto a las del Derecho Civil. 


\section{Derecho a la Posesión}

Establece el Código Civil en su artículo $850^{\circ}$ que el propietario de un bien tiene derecho a poseerlo.

Las formas que puede asumir dicha posesión están en la parte del Código Civil destinada a legislar el Derecho de Posesión y, resumidamente, se establece una amplia liberalidad en to que a este derecho se refiere, pudiendo el poseedor realizar cualquier tipo de actos posesorios sobre el objeto de su derecho, bien de acuerdo a la teoría del corpus, bien de acuerdo a la del ánimus (el artículo $825^{\circ}$ del Código Civil es bastante explícito al permitir la posesión mediata).

Distinta es la situación en la legislación agraria por dos razones:

-EI artículo 89 del D.L. 17716 establece cuales deben reputarse como actos posesorios, restringiendo de esta manera la liberalidad de las normas civiles y estableciendo, al mismo tiempo, que en caso de no poseerse en la forma por él establecida, se produce el abandono.

No sólo se está restringiendo las formas de poseer inmuebles rústicos, sino que se hace de la poseción un requisito indispensable para mantener la propiedad, lo cual refuerza la aplicación del principio básico de Reforma Agraria por el cual propiedad, tenencia y explotación son elementos intrínsecamente unidos.

- Una segunda diferencia en relación al régimen civil consiste en que, si bien la posesión mediata se permite en Derecho Agrario (el artículo $8^{\circ}$ del D.L. 17716 habla de actos posesorios "... efectuados por su dueño u otro en su nombre...") constituye causal de expropiación, tal como lo señalan claramente, entre otros, los artículos $17^{\circ}$ y $19^{\circ}$ del D.L. 17716.

Cabe señalar, sin embargo, que la existencia do una posesión mediata por el propietario no hace extinguirse su derecho sino que sólo crea la existencia de una causal de expropiación, siendo prueba de ello que el trámite de afectación se entiende con el propietario-poseedor mediato.

\section{Derecho al uso}

Aunque el artículo $850^{\circ}$ del Código Civil no menciona expresamente el uso como un derecho generado de la propiedad, convenimos en que es un derecho intrínseco al derecho de propiedad.
El Código Civil establecía determinadas limitaciones al uso del bien, que estaban señaladas en los artículos $856^{\circ}$ y siguientes y que, como hemos dicho, sólo respondian a garantizar normas minimas de convivencia humana pero, en ningún caso, eran normas de fuerza contra el derecho al uso por el propietario del bien objeto de su derecho.

Otra es la situación en la legislación agraria. En efecto, los artículos $15^{\circ}$ y $16^{\circ}$ del D.L. 17716 establecen fuertes recortes en cuanto a la forma y condiciones de uso que debe reunirse en los predios agricolas.

No los enumeraremos porque no consideramos necesario el repetirlos, pero cabe resaltar que en ellos vuelve a reflejarse la anteposición de los principios básicos de Reforma Agraria que se refieren a interés social, aumento de la producción y la productividad, etc., al libre y absoluto ejercicio de los atributos del derecho de propiedad.

Esto representa considerar los intereses globales de la sociedad como primarios y oponibles a los intereses individuales que representa la propiedad privada.

Además, como ya hemos mencionado en el punto anterior, el propietario deberá usar la tierra por si mismo, con conducción directa, atendiendo a lo establecido por el artículo $20^{\circ}$ del D.L. 17716 y sus disposiciones reglamentarias pues, de lo contrario, se caerá en causal de expropiación.

\section{Derecho al disfrute}

En lo que a este derecho respecta, nos referiremos a su forma más saltante: el arrendamiento o locaciónconducción de predios agrícolas.

Varias son las modificaciones de la Ley General de Reforma Agraria respecto al régimen liberal que contiene el Código Civil. De ellas, las principales son las siguientes:

-Declarada Zona de Reforma Agraria una región, se prohiben en ella los contratos de arrendamiento de predios agrícolas, salvo en los casos de predios de propiedad de menores, incapaces (mientras duren estas situaciones), o mientras el menor realiza estudios de profesiones estrictamente vinculadas a la actividad agropecuaria y siempre que no excedan de un periodo de seis años.

-El arrendatario tiene un retracto preferente al de los retractantes calificados por el artículo $1445^{\circ}$ y si- 
guientes del Código Civil para la adquisición del predio.

-El arrendatario, según el artículo $19^{\circ}$ del D.L. 17716 tiene derecho preferente a la adjudicación del área que hubiese venido conduciendo, en caso de que fuere expropiada.

-El articulo $129^{\circ}$ del D.L. 17716 prohibe una serie de cláusulas contractuales que podrian determinar difíciles situaciones económicas al conductor, cuando no, una explotación disfrazada por el propietario.

- Se limita considerablemente la legitimación activa para interponer acciones de desahucio y aviso de despedida por el propietario contra el conductor, según lo establecido en el art. $130^{\circ}$ del D. L. 17716.

-El tope máximo de la merced conductiva será el equivalente en dinero del diez por ciento de la producción bruta anual del fundo, estimado al momento de celebrarse el contrato.

El artículo $132^{\circ}$ del D.L. 17716 agrega que "Si la renta pactada excede el límite legal, el arrendatario podrá demandar ante el Fuero Agrario su reducción y reembolso consiguiente. Este derecho soló podrá ejercitarse dentro del término del contrato.

- Se señala seis años como plazo mínimo del arrendamiento de predios rústicos. Asimismo, se establece que si vence el término sin que el locador solicite el predio ni el conductor lo devuelva, se entiende prorrogado el contrato por un plazo igual.

-Se reforma el sistema de abono de mejoras.

-Se prohibe el sub-arrendamiento.

Finalmente, en el artículo $143^{\circ}$ del D.L. 17716 se establece la irrenunciabilidad contractual de los derechos que la ley otorga, dando a estas reglas el carácter de normas de orden público.

\section{Derecho a la reivindicación}

El artículo $8^{\circ}$ del D.L. 17716 recorta sustancialmente el plazo de prescripción extintiva de la acción reivindicatoria y demás acciones reales sobre predios rústicos, fijándolo en cinco años, con lo cual se garantiza más que en el régimen civil, la atención directa que el propietario debe a los bienes agrarios de su propiedad.

Otra norma de importancia es la contenida en el segundo párrafo del artículo 19º del D.L. 17716 que establece como causal de expropiación el litigio sobre un predio a la fecha de declaración de Zona de Reforma Agraria.

Cuando el predio cae en esta causal no puede ser reivindicado por quien tenía la propiedad, dándosele derecho únicamente al monto de la expropiación.

\section{Derecho a la disposición}

El artículo $108^{\circ}$ del D.L. 17716 ya comentado, establece limitaciones a la transferencia de la propiedad de predios rústicos en zonas de Reforma Agraria, determinando que la disposición que hace el propietario no lo desliga totalmente del derecho de propiedad que tenia sobre el bien hasta antes de transmitirlo.

El régimen de parcelaciones por iniciativa privada establece varios requisitos para dividir un predio $y$ transferir las parcelas resultantes: aprobación de la parcelación o independización por la Dirección General de Reforma Agraria y Asentamiento Rural y un régimen estricto de delimitación y transferencia de parcelas introducido por el D.L. 18003, ahora incorporado al Título IX del D.L. 17716 en su Texto Unico Concordado.

\section{Conclusión}

A través del desarrollo que hemos realizado, puede verse como la legislación agraria ha establecido una serie de principios básicos sobre propiedad de predios rústicos en los cuales, a diferencia de lo prescrito por el Código Civil, se prefiere con mucha claridad el interés social a los intereses individuales que representa el ejercicio libre de la propiedad privada.

De esta manera, se reforma sustancialmente la concepción del derecho de propiedad haciéndolo girar en torno a tres elementos indesligables: propiedad-tenencia-explotación directa a través del trabajo.

Ello se trata de lograr haciendo más accesible la prescripción adquisitiva a quien trabaja directamente la tierra; configurando el abandono como una suerte de prescripción extintiva del derecho de propiedad; estableciendo sanciones de pérdida del derecho de propiedad por usarla contra el interés social, y anteponiendo la interpretación objetiva de la realidad social y económica a las formalidades legales.

Se limita el derecho a la posesión que otorga el derecho de propiedad, estableciendo sólo determinados 
actos como posesorios y convirtiendo la posesión mediata en causal de expropiación.

Se limita el derecho al uso, exigiendo conducción directa con actos posesorios tipificados por la legislación y estableciendo sanciones de expropiación a los predios que no sean debidamente explotados, de acuerdo a lo establecido por los artículos $15^{\circ}$ y $16^{\circ}$ del D.L. 17716.

Se limita el derecho al disfrute a través de una rígida reglamentación del contrato de locación-conducción de predios agrícolas.
Se limita el derecho a la reivindicación acortando el plazo de la prescripción extintiva de las acciones reales y estableciendo como causal de expropiación la existencia de litigio sobre un predio agricola a la fecha de declaración de Zona de Reforma Agraria.

Finalmente, se limita el derecho a la disposición a través del artículo $108^{\circ}$ del D.L. 17716 y a través de las normas sobre parcelación e independización de predios rústicos contenidas en el Título IX del mismo cuerpo legal. 